\title{
The Impact of the Contribution Micro-environment on Data Quality: The Case of OSM
}

\author{
Vyron Antoniou* and Andriani Skopeliti ${ }^{\dagger}$ \\ ${ }^{*}$ Hellenic Army General Staff, Geographic Directorate, PAPAGOU Camp, \\ Mesogeion 227-231, Cholargos, 15561, Greece, v.antoniou@ucl.ac.uk \\ †School of Rural and Surveying Engineering, National Technical University of \\ Athens, 9 H. Polytechniou, Zografou, 15780, Greece
}

\begin{abstract}
OpenStreetMap (OSM) is the most successful example of Volunteered Geographic Information (VGI). It is also the most frequently used case study in research that focuses on VGI quality, as it is usually considered a proxy for other VGI projects. The research in this area usually focuses on comparisons with authoritative data, measurements and quality statistics. In other papers, scholars have explored quality frameworks or studied the motivation and engagement of volunteers. This chapter examines OSM quality from a different point of view. The focus here is on examining how the qualitative elements of the micro-environment within OSM, such as data specifications and the OSM editors, have evolved over time. We discuss how their evolution can affect OSM data quality, taking into account a number of different factors and dimensions that directly affect the quality of the contributions.
\end{abstract}

How to cite this book chapter:

Antoniou, V and Skopeliti, A. 2017. The Impact of the Contribution Microenvironment on Data Quality: The Case of OSM. In: Foody, G, See, L, Fritz, S, Mooney, P, Olteanu-Raimond, A-M, Fonte, C C and Antoniou, V. (eds.) Mapping and the Citizen Sensor. Pp. 165-196. London: Ubiquity Press. DOI: https://doi. org/10.5334/bbf.h. License: CC-BY 4.0 


\section{Keywords}

Spatial data quality, OSM specifications, OSM editors, quality evaluation

\section{Introduction}

OpenStreetMap (OSM) is one of the first examples of Volunteered Geographic Information (VGI; Goodchild, 2007), and continues to be one of its prime examples. VGI has been defined as 'the widespread engagement of large numbers of private citizens, often with little in the way of formal qualifications, in the creation of geographic information' (Goodchild, 2007). A number of factors have helped this phenomenon to grow, including the removal of the selective availability of the Global Positioning System (GPS) in 2000 (Clinton, 2000), which has resulted in the proliferation of GPS-enabled devices, novel Web 2.0 practices and programming techniques as well as the development of spatial applications and products based on global-wide maps of satellite imagery by technology giants such as Google, Microsoft and Yahoo!. Since 2007, VGI has become intertwined with crowdsourcing, active local communities and social media, and thus can be found in many flavours and extracted from various sources (for more details, see Chapter 2 by See et al., 2017), such as web applications about toponyms, GPS tracks, sharing of geotagged photographs, synchronous micro-blogging, social networking sites, etc. A very interesting, and equally promising, interconnection of VGI is the one with the domain of citizen science (Haklay, 2013). As the latter gains momentum, the need for geotagged measurements and information is growing, and along with it the quest for solid answers about the caveats and challenges that VGI projects face, especially with respect to data quality. Thus, understanding how the most successful VGI project (i.e. OSM) has evolved in terms of quality will give insights valuable to other existing VGI projects or projects that will follow in the future, including those in the citizen science domain. Spatial data quality is the cornerstone of every spatial database, map, product or service. Measuring, understanding and documenting the quality of spatial data is of paramount importance for any kind of geodata, including VGI.

This chapter will examine OSM quality evolution from a new point of view. In Section 2, quality evaluation procedures, as described in the ISO quality framework, will be discussed. Then, in Section 3, the methodology for understanding the evolution of OSM quality will be introduced. The central focus will not be on the data themselves (as is usually the case in most OSM-based quality studies), but rather on the micro-environment inside which OSM is evolving. To this end, Section 4 will cover the evolution of OSM specifications, taking into account a number of different factors and dimensions that directly affect the quality of contributions; in Section 5, the evolution of OSM editors will be examined, as they are literally the entry point for all OSM contributions. Both 
Sections will provide a critical view of the developments on these two fronts and of their impact on the overall quality of OSM. The chapter will conclude with a discussion of and conclusions on how all of these aspects can provide a useful context for OSM quality evaluation.

The purpose of this chapter is not to provide measurements or quantitative reports regarding the quality of OSM. Instead, the aim is to highlight new, important facets of OSM quality that have not been considered to date in what is otherwise a rich and growing literature on VGI quality. This chapter supports the idea that the evolution of OSM data quality is closely related to qualitative elements of the OSM micro-environment. These include the wiki-based and thus bottom-up build and constantly changing specifications, the digitisation software (i.e. the OSM editors), the mapping parties, the forums, the voting system, the local and global OSM communities, the few, yet most productive, contributors, and other seemingly small and unimportant factors that in reality determine to a great extent the evolution of the OSM initiative and consequently the quality of the data created. All of these factors are outside the traditional quality elements for spatial data (ISO, 2005) or even the new quality indicators suggested specifically for VGI (see Antoniou and Skopeliti, 2015 for an overview of these). This chapter focuses on two of these outside factors: OSM specifications and OSM editors.

\section{Spatial Data Quality Evaluation Procedures}

This book provides considerable material on the subject of spatial data quality. For example, in Chapter 7, Fonte et al. (2017) discuss VGI quality and review measures and indicators for this new breed of data. In Chapter 9, Skopeliti et al. (2017) discuss best practices and methods for visualising VGI quality, while Chapter 10, by Minghini et al. (2017), discusses best practices for data collection, including quality considerations. Finally, in Chapter 13, OlteanuRaimond et al. (2017) examine the experience of European National Mapping Agencies (NMAs) with VGI data and discuss methods for obtaining contributions of high quality from volunteers.

Both in this book and in the literature available on the subject of VGI quality, most VGI cases or examples come from the OSM project. OSM is a prime example of VGI as it has managed to provide free, constantly updated, crowdsourced data for the globe. However, when research focuses on VGI data quality, scholars tend to examine some of the spatial quality elements for a given study area, e.g. cities, urban areas or nationwide (Antoniou, 2011; Girres and Touya, 2010; Haklay et al., 2010; Jokar Arsanjani et al., 2015). The studies usually follow a benchmark evaluation process, which involves creating a copy of what is a continuously changing dataset, and then evaluating this copy as if it were a static dataset. This method gives insight into the data quality at the time when the copy was created; thus, these efforts provide a good understanding of selected 
quality elements at a given point in time compared with corresponding authoritative datasets. However, spatial datasets, and especially VGI ones, are not static products and hence time is a critical factor that is not often considered. The starting point for a spatial product is the specifications that will be used to create the dataset. Yet these specifications can change over time for both authoritative and VGI datasets. In fact, the latter kind of Geographic Information (GI) is more susceptible to changes in specifications since bottom-up processes provide the flexibility for new rules to be established or existing ones deprecated more easily by the community of volunteers. While the path of evolution and change in the specifications of a product is inescapable, there is a fundamental difference in how each source of GI (i.e. authoritative or VGI) handles their dataset life-cycle. For example, authoritative data, collected by NMAs or Commercial Mapping Companies (CMCs), usually follow a versioning system. Users of such data are notified that a set of updates is available or, more relevant to our case, that a new dataset has been created based on new specifications. The product specifications can also be available to the interested parties. A case in point can be found in the practices of the UK's Ordnance Survey (OS). For the OS MasterMap product (OS 2001), for example, OS provides a detailed document that explains how each physical entity is conceived, modelled and stored and thus what accuracy and attributes should be expected. The important point here is that while a new dataset is developed, or during the migration from one form of specification to another, the datasets are not accessible to the users. This process takes place in-house, and only when the whole process has been concluded are the data available for use. This is in contrast with what takes place with VGI. In a sense, VGI datasets are following one of the main characteristics of Web 2.0 (O’Reilly, 2007), i.e. perpetual beta. This small phrase is usually applied to software development cycles, and means that there are no versioning cycles but rather a continuous effort of software development so as to match evolving user needs; here this notion spills over to datasets, and OSM is an excellent example for monitoring this. The perpetual editing of and changes to OSM specifications has made OSM evolve from a dataset with a handful of layers and physical features to an extremely detailed dataset, in many cases far more detailed than any NMA or CMC dataset. The difference between VGI and authoritative data is that in VGI while the evolution of datasets takes place the actual data are available without any guarantees or indications regarding the state or compliance of each feature in relation to a specification's version. It is not difficult to imagine that this process, while it has many advantages, can create a series of inconsistencies and, in fact, deteriorate the overall quality of the data.

Thus, while specification improvements might eventually be a necessary step for a better, more inclusive, detailed and meaningful dataset, during the transition time, the dataset is bound to suffer from inconsistencies, mixed feature versions and mixed typologies that exist in former and latter specifications. This is even more likely if there is a perpetual change in specifications without any rigorous provision on how to manage the data transition and compliance. 
Returning the discussion to quality evaluation processes, benchmark comparisons are usually chosen not because they are necessarily the best way to evaluate the data quality of a VGI dataset but because they are the most practical to perform and report. ISO (2005) explains that benchmark procedures should be based on the establishment of a suitable reporting frequency. Sporadic and non-systematic evaluations, although perfectly acceptable in an academic environment, do not provide a clear view of OSM quality, or of the quality of any other VGI source. To this end, a different approach suggested by the ISO quality framework is to evaluate constantly changing datasets, as is the case of OSM data, using a continuous process. Here, the starting point could again be a benchmark test, but then there should be a continuous evaluation of the updates and of the impact that these updates might have on the overall dataset. However, there is no provision made for specification migration, perhaps because this sense of perpetual editing is not applicable to authoritative data.

\section{Methodology}

To evaluate OSM evolution from a quality point of view, we need to consider what process to use. A way forward is to follow one of the two ISO suggestions. This means that we need to develop a benchmarking method that will be able to examine an instance of the OSM data against an authoritative dataset on a regular basis (e.g. weekly, monthly, etc.). For a number of reasons, this is not straightforward. First, there is no global-scale authoritative dataset that could play the role of the reference data. Even if such datasets were available for academic research, it is not clear which one would be more detailed and at which places. For example, Vandecasteele and Devillers (2015) report that in many places OSM is far more detailed than any authoritative dataset available. Moreover, such an approach would require the implementation of considerable amounts of brute force computing on a regular basis. This approach would be possible in the context of confined academic experiments that would test either a few quality elements at a national level or all the quality elements for small areas, but it would be difficult to achieve and maintain both globally and regularly. The same applies to a continuous evaluation process, although the evaluation of the quality of OSM updates is a more straightforward task, given the fact that OSM provides regular updates in separate files and for various time intervals. However, the frequency of updates is inversely related to the number of changes, so, for practical reasons, evaluating the data quality continuously is beyond the means of most NMAs or CMCs.

Hence, an alternative approach is taken here, which is based on the evaluation of factors that directly affect OSM quality but are currently not studied by researchers, i.e. a study of the OSM specifications. The value of specifications in VGI has been discussed by Brando and Bucher (2010) and by Brando et al. (2011). The form of, and the rules included in, a product's specification, at any 
given point in time, is fundamental. This, along with metadata, is the starting point that allows potential users to understand the usability of the data. Monitoring and documenting the changes that have taken place in the specification of OSM over time could add another tool to the toolbox used for OSM quality evaluation, and could provide the necessary context for some of the academic efforts in this field.

Moreover, this approach will be coupled with an evaluation of the evolution of OSM editors. OSM contributions are uploaded through a number of OSM editors that have been developed and updated by the OSM community itself. The editing tools and the overall functionality of the editor, and, more importantly, the editor's conformance to the wiki specifications, play a significant role in the kind of edits submitted and consequently in the quality of the data contributed.

\section{Evolution of OSM Specifications}

\subsection{General Changes to the Main OSM wiki Page}

OSM specifications are described in a wiki-based process. The starting point is a MediaWiki ${ }^{1}$ web page titled 'Map Features' (OpenStreetMap, 2016). This page lists all of the physical features that should be included in the OSM database, along with some of the basic attributes that should describe each feature. The OSM community decides what is added or removed from this list through a voting system. In the OSM world, the features are called keys and the attributes values. In the 'Map Features' web page, the physical features are grouped into categories and sub-categories depending on their semantics and nature. For each feature, additional information is available, such as the type of geometry that should be used (i.e. node, way or area), comments on what each feature represents, assisting documentation from Wikipedia, a photograph that shows how the feature appears on the OSM map and a photograph that functions as a photo-interpretation key. The latter photograph helps the contributors to better understand how to assign features on the ground to the OSM nomenclature. Moreover, each key/tag combination is further explained in other wiki pages, which themselves include more details about the way the feature should be digitised, additional attributes that could further describe the feature, and the possible combinations of the attributes.

For web pages created with MediaWiki, it is possible to access the pages' history and trace back what changes have been made, at which time and by whom. Moreover, a short summary of the changes is available, along with a classification of whether a change was a minor edit or not (computed based on whether the person who performs the edit has marked the edit as minor or not ${ }^{2}$ ). Thus, in order to understand how this (quasi) specification of OSM has evolved, we examined how the 'Map Features' page has changed over time. At the time of 
writing (May 2016), there were 847 versions of this wiki page alone, with the first one dating back to 20 December 2005. This means that a major or minor edit has taken place approximately every 4.4 days since on average.

The first point of analysis was to examine when each version was released. Figure 1 shows the number of changes per year and the corresponding percentage. This provides a good understanding of whether OSM specifications are constantly changing or if there are any emerging patterns. Figure 1 shows that most of the changes ( $88 \%$ ) have taken place in the first three years of OSM's life, while, from 2011 onwards, each year's overall changes do not exceed $2 \%$ of the total of changes. This is an interesting observation as it paints a picture of a crowdsourced product that has matured extremely fast compared to the breadth and length of its aims (i.e. to 'create and distribute free geographic data for the world's ${ }^{3}$.

The next step is to analyse the importance of these changes. Taking into account the automatic assignment of an edit into minor or not, we explored when and how many edits take place each year for each kind of change. It is understandable that the number of characters changed cannot be an entirely safe measure of a change's importance. However, it is considered as a good indicator that can give a basic understanding of the amount of work put forward in every change. Figure 2 presents the percentage of major and minor changes per year. Despite being a fast maturing product as noted above, major changes in the specifications take place constantly. This observation should be considered in combination with that of the flexibility provided to contributors, which is in line with the openness and spirit of inclusiveness that characterises the OSM project. For example, in the wiki-forums it is explicitly stated that the OSM community might introduce best practices, guidelines or even deprecated features and attributes and that nothing is banned. Contributors are free to add whatever they believe will better describe the physical world.

Thus, inconsistencies and mismatches in the keys and values used can come from both a 'formal' change in the specifications and the free key/tag combination choice available to users. Interestingly, in the case when changes in the specification are introduced, automatic correction of the existing features is highly discouraged; the rules state: 'Under no circumstances should you automatically (or semi-automatically) change "deprecated" tags to something else in the database on a large scale without conforming to the Automated Edits code of conduct. Any such edits will be reverted'4.

\subsection{Development of Feature Specifications}

The analysis so far has provided an initial overview of OSM specification's development over time. Now the focus turns to the actual changes that took place. For practical reasons, a selection of some of the 847 'Map Features' page versions had to be made in order to use them for comparison. The 


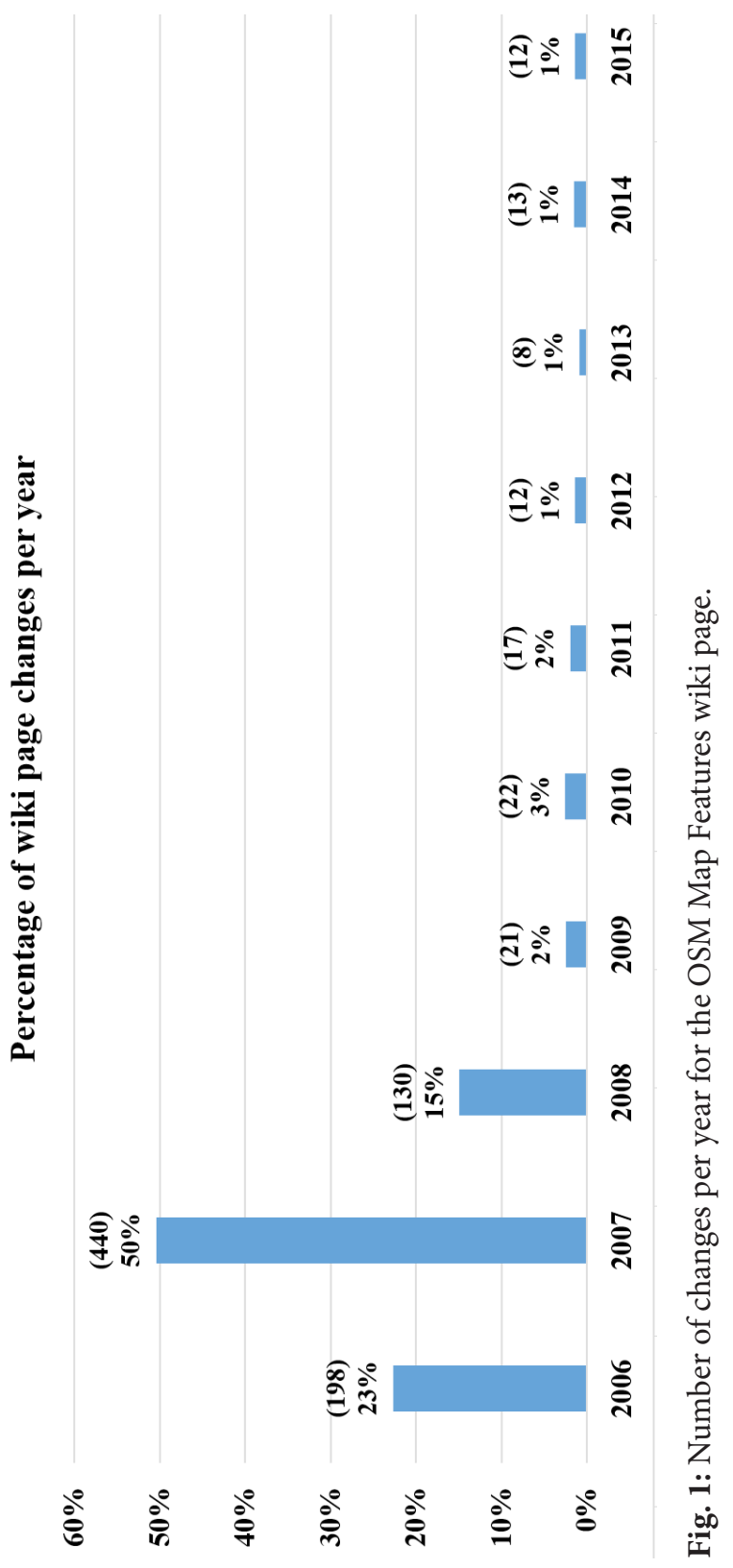




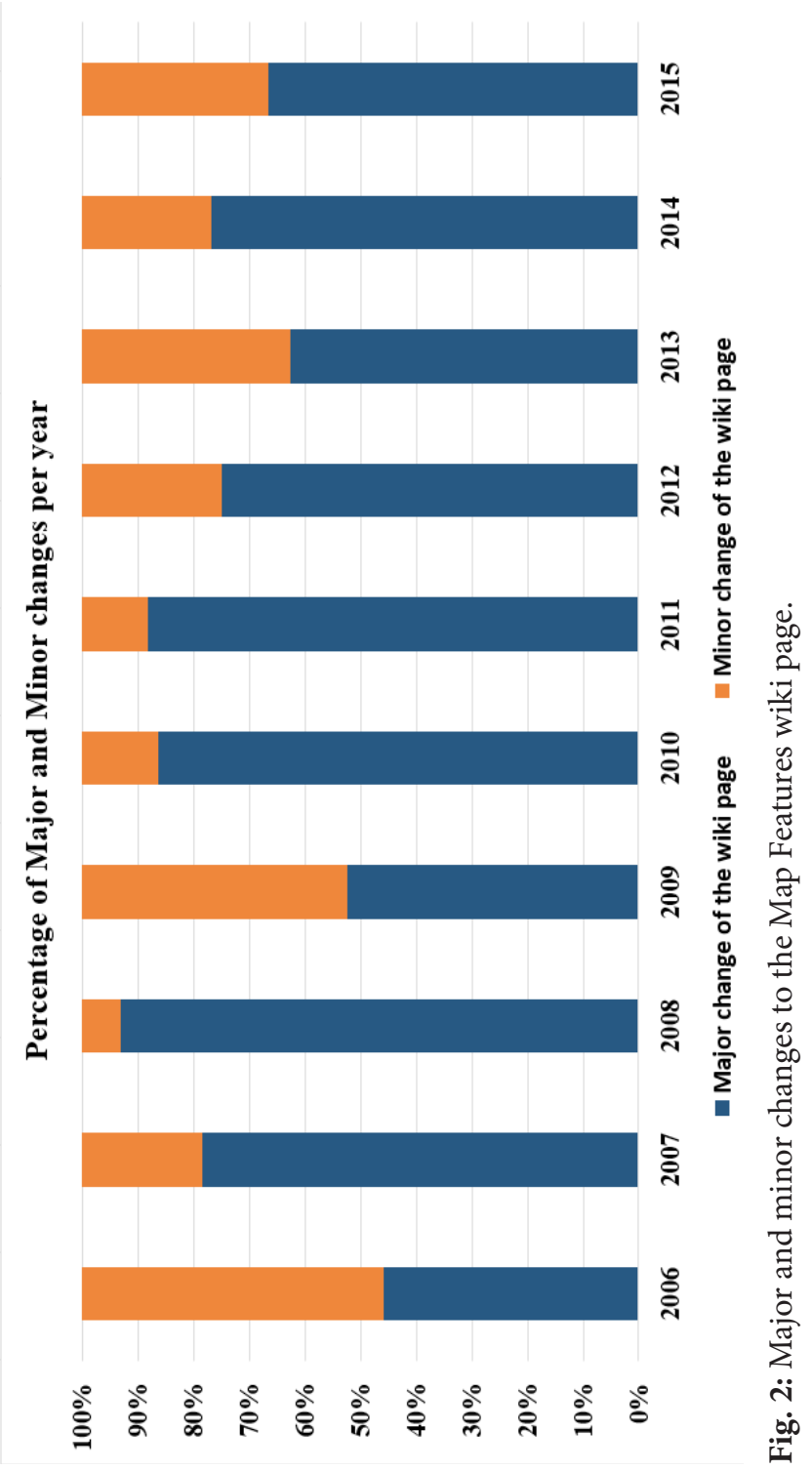


versions selected were those closest to the end of each calendar year from 2006 up until 2015. Then, in order to better monitor the development of the specification, we examined the alterations that took place in four dimensions: the vertical, horizontal, in-depth and internationalisation dimensions. All four dimensions are closely related to the OSM data (in fact are different aspects of the OSM content) and thus can provide a helpful point of view in the effort to assess data quality. We define the vertical dimension as the number of physical features described in the wiki page, while the horizontal dimension is the information available for each feature (i.e. keys, values, comments, rendering instructions and photographs; all of these are helpful in guiding the contributors to correctly capture physical features). The in-depth dimension is considered to be the extra information available for each feature: both keys and tags are usually further analysed in separate wiki pages where, for example, possible key/value combinations or more detailed instructions about their proper use are provided. Finally, the internationalisation dimension is defined as the availability of the specification in different languages. In general, wiki pages can be translated and exist simultaneously in different languages, and thus can be read and accurately comprehended by many people around the world; similarly, OSM specifications need to be understood by the largest possible audience in order to successfully achieve the aim of creating a global map.

A number of illustrative examples are provided for each dimension. These examples aim to provide a picture of the changes that have taken place in the OSM specification over time and help researchers understand both the volatility in the contributions and the quality that comes from the micro-environment in which OSM is developing.

\subsubsection{Changes in the Vertical Dimension}

One interesting aspect in the evolution of the OSM specification is to examine how the major OSM categories have evolved. This vertical examination of the 'Map Features' page gives a sense of how the nomenclature of OSM has changed through the addition and removal of categories and features in the list of entities that OSM uses to describe the world. Table 1 shows the number of active categories at the end of each calendar year; moreover, it shows how many categories have been added or removed compared to the previous year.

It can be seen that major additions took place during 2008, where 48 categories were added. From then, new feature categories are added almost every year, but interestingly there are also categories that have been removed as independent typologies in the nomenclature of OSM and have been merged with others. Examples of the categories added include power and shop in 2007, facilities, education and transportation in 2008, geological in 2009, emergency, 
Table 1: Additions and removals of OSM categories from the Map Features wiki page.

\begin{tabular}{|l|c|c|c|c|c|c|c|c|c|c|}
\hline & $\mathbf{2 0 0 6}$ & $\mathbf{2 0 0 7}$ & $\mathbf{2 0 0 8}$ & $\mathbf{2 0 0 9}$ & $\mathbf{2 0 1 0}$ & $\mathbf{2 0 1 1}$ & $\mathbf{2 0 1 2}$ & $\mathbf{2 0 1 3}$ & $\mathbf{2 0 1 4}$ & $\mathbf{2 0 1 5}$ \\
\hline $\begin{array}{l}\text { Categories } \\
\text { Present }\end{array}$ & 28 & 32 & 78 & 83 & 90 & 97 & 91 & 93 & 96 & 93 \\
\hline $\begin{array}{l}\text { Categories } \\
\text { Removed }\end{array}$ & & 0 & 2 & 0 & 0 & 0 & 4 & 0 & 0 & 3 \\
\hline $\begin{array}{l}\text { Categories } \\
\text { With a Name } \\
\text { Change* }\end{array}$ & 0 & 0 & 0 & 0 & 0 & 2 & 0 & 0 & 0 \\
\hline $\begin{array}{l}\text { Categories } \\
\text { Added* }\end{array}$ & 4 & 48 & 5 & 7 & 7 & 0 & 0 & 3 & 0 \\
\hline${ }^{*}$ compared to the previous year & & & & & & & & & & \\
\hline
\end{tabular}

medical rescue and firefighters in 2010, commercial and civil amenity in 2011 and traffic calming in 2014. Examples of removals include the categories of cycleway, tracktype, abutters and naming in 2012.

Apart from the changes in the major OSM categories, there have also been changes recorded to the features in each category. Tables 2, 3 and 4 present illustrative examples of how selected features have evolved over time. More specifically, Table 2 shows the sub-categories of Highways and Places as well as the number of distinct features included in each of these sub-categories. It can be seen that, for these two major categories, which in fact include all road network and all gazetteer data, there have not been any changes since 2008. This does not mean that there have not been changes in the wiki pages that further explain the attributes of each distinct feature, but that at least at this high level the nomenclature has been stable since 2008. The flip side is that while the geometry (i.e. positional accuracy) of the road network or places might still be correct, since they have not been updated since 2007 it is likely that they might suffer from attribution inconsistencies that affect their thematic accuracy and logical consistency.

Table 3 shows how the Buildings category has evolved. Here again, at the subcategories level and in terms of the number of features per sub-category, Buildings have been stable since 2011. The interesting point here is that this major category, which includes the footprints of buildings, was introduced in OSM in 2011. Thus, areas that have not been updated since 2011, either because there was a bulk upload in the past or because the area was mapped by a very productive user that did not return to update it (for more, see Antoniou and Schlieder, 2014), would probably not have this type of feature, since capturing buildings was out of the scope of OSM before 2011. 
Table 2: The number of sub-categories and distinct features (keys) included in the Highways and Places main OSM categories from 2006 to 2015.

\begin{tabular}{|c|c|c|c|c|c|c|}
\hline \multirow{2}{*}{$\begin{array}{l}\text { Primary } \\
\text { Feature } \\
\text { Category }\end{array}$} & \multirow[t]{2}{*}{ Feature Sub Category } & 2015 & 2014-2009 & 2008 & 2007 & 2006 \\
\hline & & \multicolumn{5}{|c|}{ Distinct Features (Keys) } \\
\hline \multirow{10}{*}{ 赵 } & Roads & 8 & \multirow{10}{*}{ No change } & 8 & \multirow{10}{*}{$47^{*}$} & \multirow{10}{*}{$42^{*}$} \\
\hline & Link roads & 5 & & 5 & & \\
\hline & Special road types & 6 & & 6 & & \\
\hline & Paths & 4 & & 4 & & \\
\hline & $\begin{array}{l}\text { When sidewalk (or } \\
\text { pavement) is tagged on } \\
\text { the main roadway }\end{array}$ & 1 & & 1 & & \\
\hline & $\begin{array}{l}\text { When cycleway is drawn as } \\
\text { its own way }\end{array}$ & 1 & & 1 & & \\
\hline & $\begin{array}{l}\text { Cycleway tagged on the } \\
\text { main roadway or lane }\end{array}$ & 8 & & 8 & & \\
\hline & Lifecycle & 2 & & 2 & & \\
\hline & Attributes & 27 & & 27 & & \\
\hline & Other highway features & 18 & & 18 & & \\
\hline \multirow{5}{*}{ 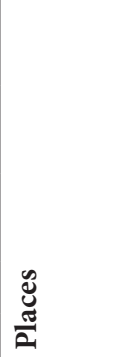 } & $\begin{array}{l}\text { Administratively declared } \\
\text { places }\end{array}$ & 7 & \multirow{5}{*}{ No change } & 7 & \multirow{5}{*}{$15^{*}$} & \multirow{5}{*}{$15^{*}$} \\
\hline & $\begin{array}{l}\text { Populated settlements, } \\
\text { urban }\end{array}$ & 7 & & 7 & & \\
\hline & $\begin{array}{l}\text { Populated settlements, } \\
\text { urban and rural }\end{array}$ & 6 & & 6 & & \\
\hline & Other places & 6 & & 6 & & \\
\hline & Additional attributes & 6 & & 6 & & \\
\hline
\end{tabular}

Finally, Table 4 shows the changes in the Additional Properties category. This category was introduced in 2012 as a successor to the Naming category, and includes important features and information such as Addresses, Annotation and Name. However, it can be seen that there are frequent and important changes in OSM typology that make it difficult for contributors to follow all the specification's provisions. For example, Addresses did not exist until 2008; it was later added to the Naming category, and then, in 2012, it was re-assigned to Additional Properties. Similarly, Place was removed from the Additional Properties category and formed a new one. 


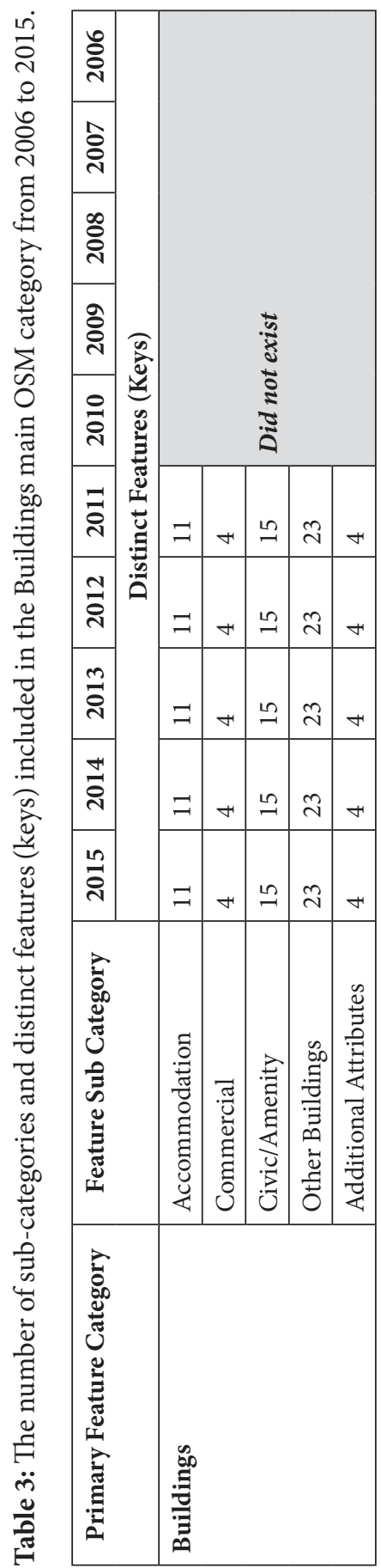




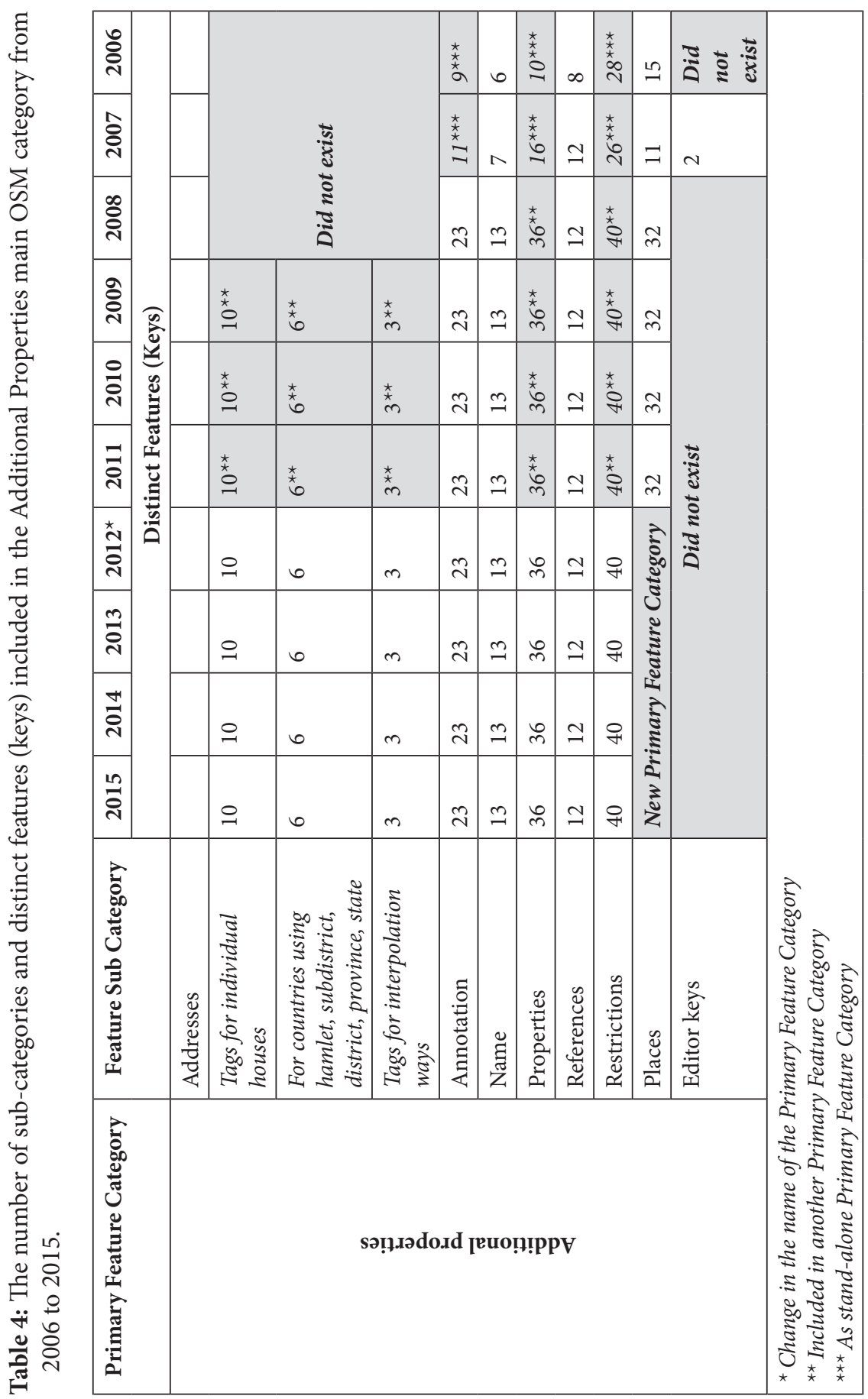


Apart from the distinct feature keys that have been added or removed over time, major changes in how the OSM community models the world took place in 2008 and 2012. In 2006, the world, according to OSM, was divided into a number of major categories: Physical, Non Physical, Abutters, Accessories, Properties, Restrictions, Naming and Annotation. During the next year, these major categories were further enriched with sub-categories, and then, in the following year, there was another typology. Indeed, in 2008 there were only three major categories: Physical, Non-Physical and Naming. The first category went from including 17 sub-categories to including 59, while the second included as subcategories all the major categories of 2007 apart from those specifically related to the naming process (e.g. Name, References, Places, Annotation, etc.), which were assigned to the last main category.

In 2012, the features were re-assigned into two new major categories: Primary Features and Additional Properties. The Physical sub-categories were added to the former category, but it also included sub-categories from the Non-Physical, such as Route, Boundary and Sport. The latter category remained with six main sub-categories: Addresses, Annotation, Name, Properties, References and Restrictions. Also, in 2012, some major changes took place regarding the grouping of the physical entities in various sub-categories and classes. For example, the entity Places, which used to be a class under the Naming subcategory in 2011, became an independent sub-category in 2012 below the Primary Features, while the Naming sub-category was assigned to the Additional Properties category. Furthermore, during the study period (i.e. 2006-2015), considerable volatility was recorded in some sub-categories. A case in point is the Naming sub-category, which listed 3 features in 2007, 9 features in 2008 and 13 features in 2009 (before it was split again in 2012).

While these are only some illustrative, and perhaps confusing, examples of the changes recorded in the OSM specification, two things are evident with respect to the commitment of contributors. First, for OSM contributors that have been consistently contributing during the entire period, it should have been difficult to meticulously follow all of the changes; thus, it should not come as a surprise that even experienced users might have introduced errors and inconsistencies in the data. On the other hand, there are either occasional contributors or contributors that have just a short active period and never contribute again; for both of these types of contributors, the best case scenario would be that contributors have consulted the active specification at a specific point in time and collected the data based on this version. In the worst case, the contributions were based on previous knowledge and understanding of the specification. In any case, and taking into account the fact that automatic corrections are discouraged, it is highly likely that a considerable number of contributions are out of date in terms of specification compliance. This also puts quality frameworks that are based on contributor evaluation under fresh scrutiny (see e.g. D’Antonio et al., 2014; van Exel et al., 2010). 


\subsubsection{Changes in the Horizontal Dimension}

The 'Map Features' page, apart from the addition and removal of new categories, sub-categories and features, has also changed in terms of the available information for each of these categories and features. While modest changes have been recorded compared to the vertical dimension, this horizontal dimension still plays a significant role in the rules and information that volunteers are equipped with when collecting data and contributing to the project.

Two illustrative examples are presented to show the evolution in the horizontal dimension. The first example (Figures 3 and 4 ) shows one of the major physical entities: Highways. Even from the early days of the OSM project, it was made clear that volunteers needed as much information as possible in order to be able to unequivocally distinguish between and capture various physical entities. However, the actual information available was not enough for safely guiding volunteers. For example, at the end of 2006 (Figure 3), the main feature-attribute combination, which is a description of what each feature name represents and how features are portrayed on the OSM map, became available. Thus, in practice, a volunteer could use only the short description as a guide for interpreting the entity before digitising and assigning it to the correct category. For more information, the volunteer would have had to follow a link attached to the Highway key. At the end of 2006, a small number of photographs and basic information was available so as to guide the contributors. It is obvious that the incomplete description of each feature, although it does not stop contributors collecting the data, makes the collection error prone in terms of thematic and logical consistency, and especially so at a time when satellite imagery was not so common and was of low resolution when it was available.

In contrast, Figure 4 shows the current specification section of Highways. The available information for each physical feature has expanded to include a photo-interpretation key that can more easily guide contributors. Furthermore, apart from the link attached to the highway key, which links to a page more detailed than the 2006 one, each value also has its own wiki page (see also Section 4.2.3). In these pages, more details are provided regarding what is preferable for the volunteers to follow and what to avoid. Moreover, a wide list of possible key-value combinations is provided, with explanations and examples.

A similar example is provided by contrasting the 2006 and 2015 wiki pages on aerialways (Figures 5 and 6). As this feature is not one of the fundamental entities of a base map, there was only a basic description of it in 2006 (Figure 5; note also that the structure of the table is different from that of the table for the highways of 2006). In contrast, in 2015 (Figure 6), the available information is as complete as that of the highways. Moreover, the comments are supported by Wikipedia articles and some basic instructions are given about the key-value information. 


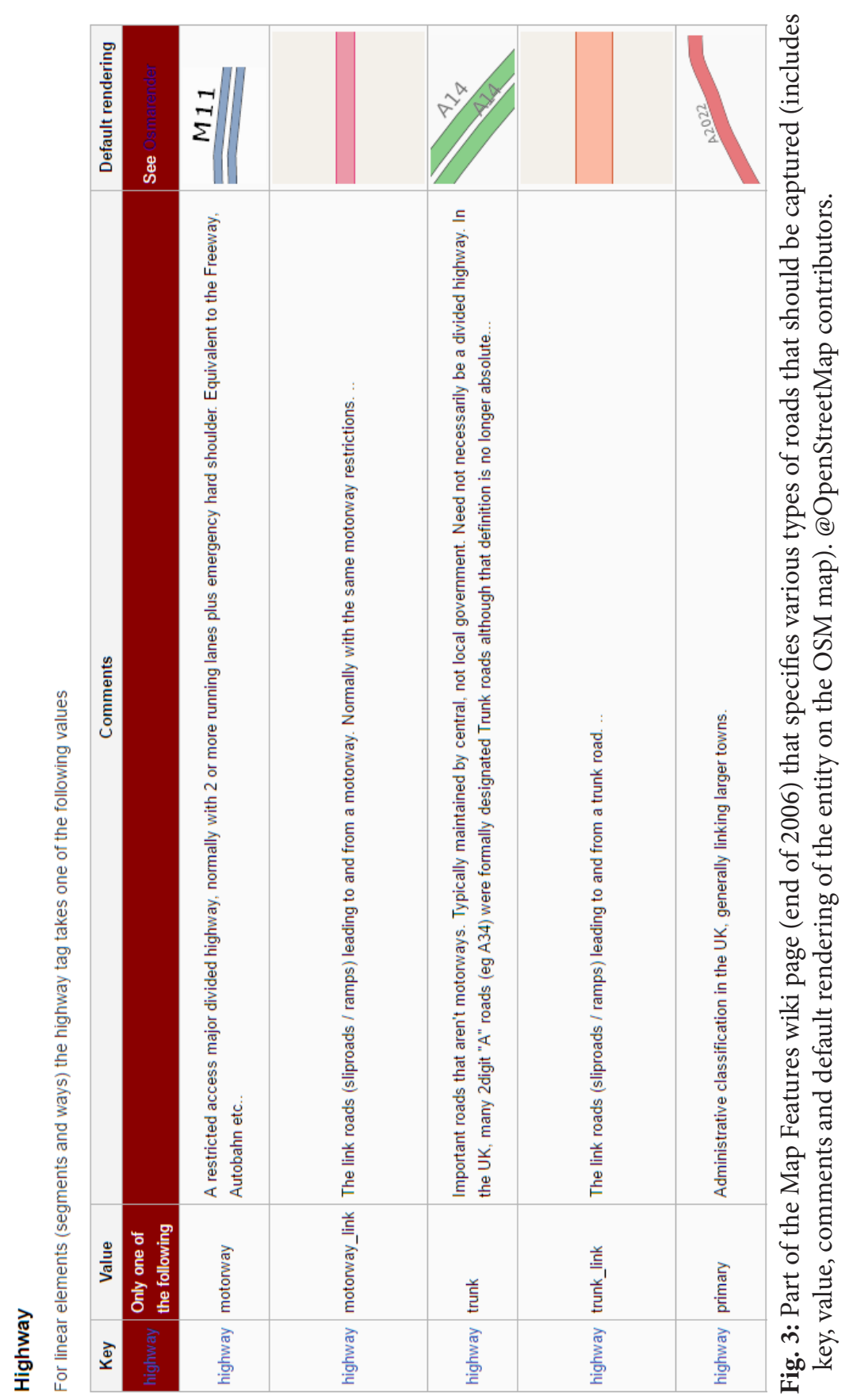




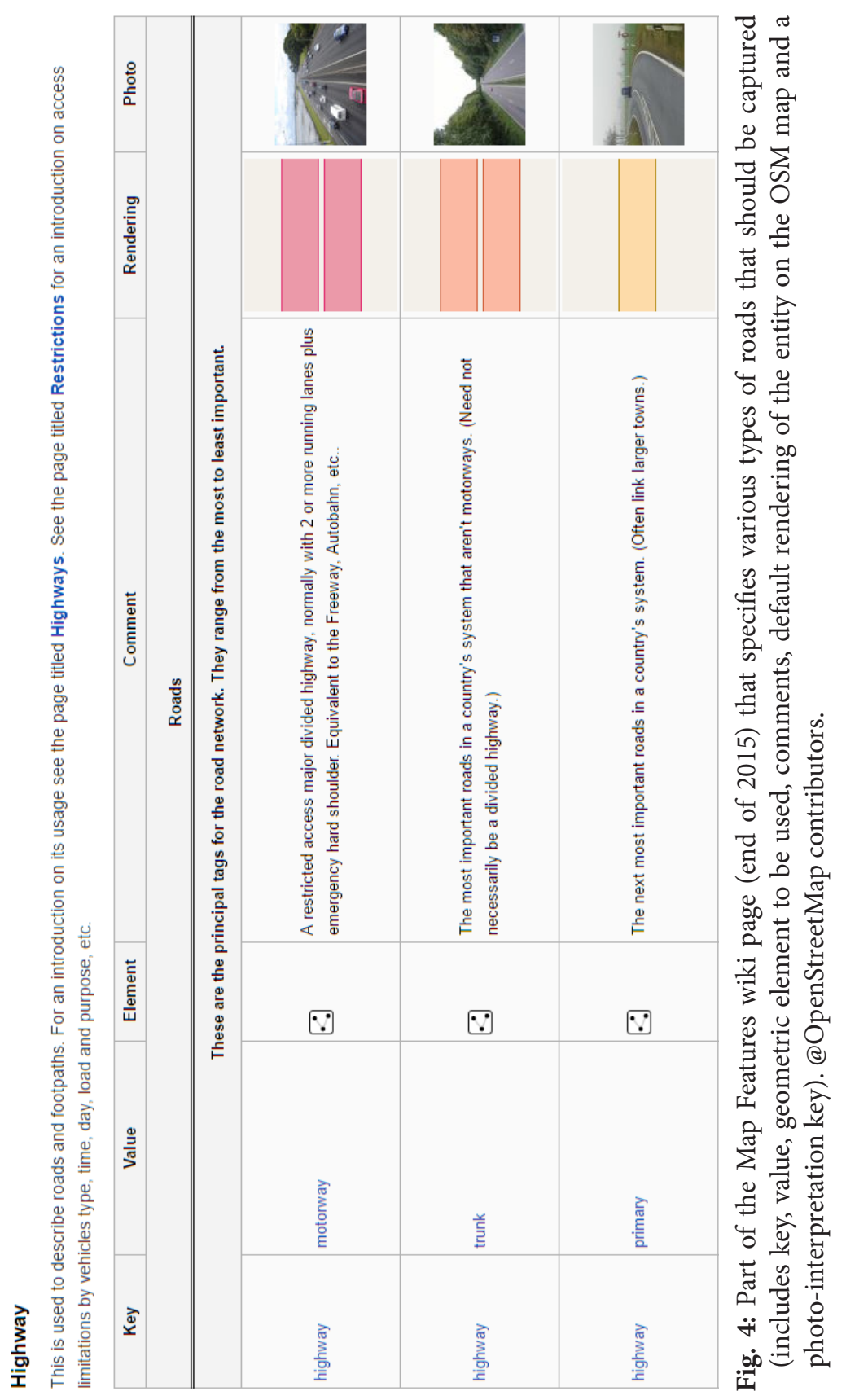




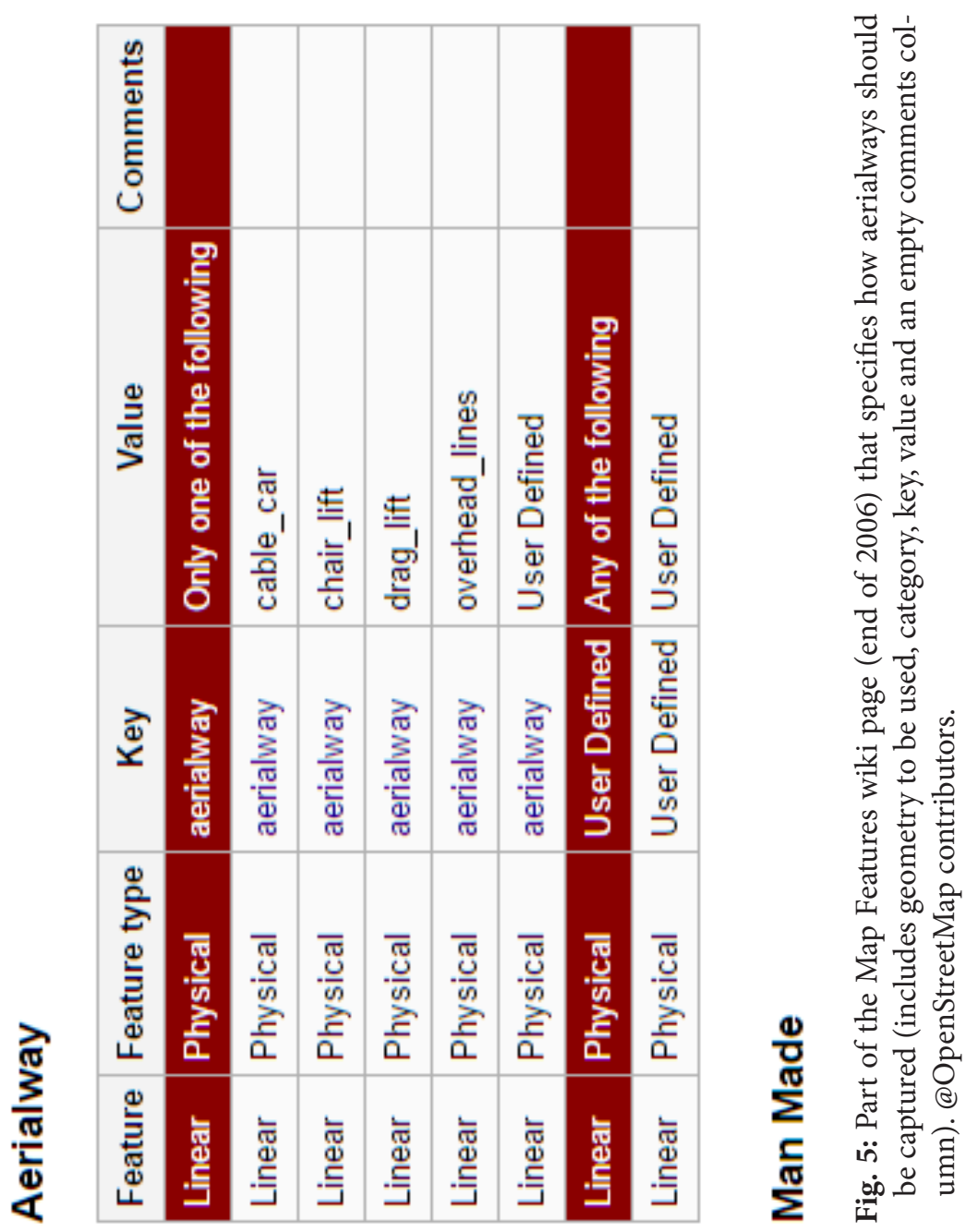




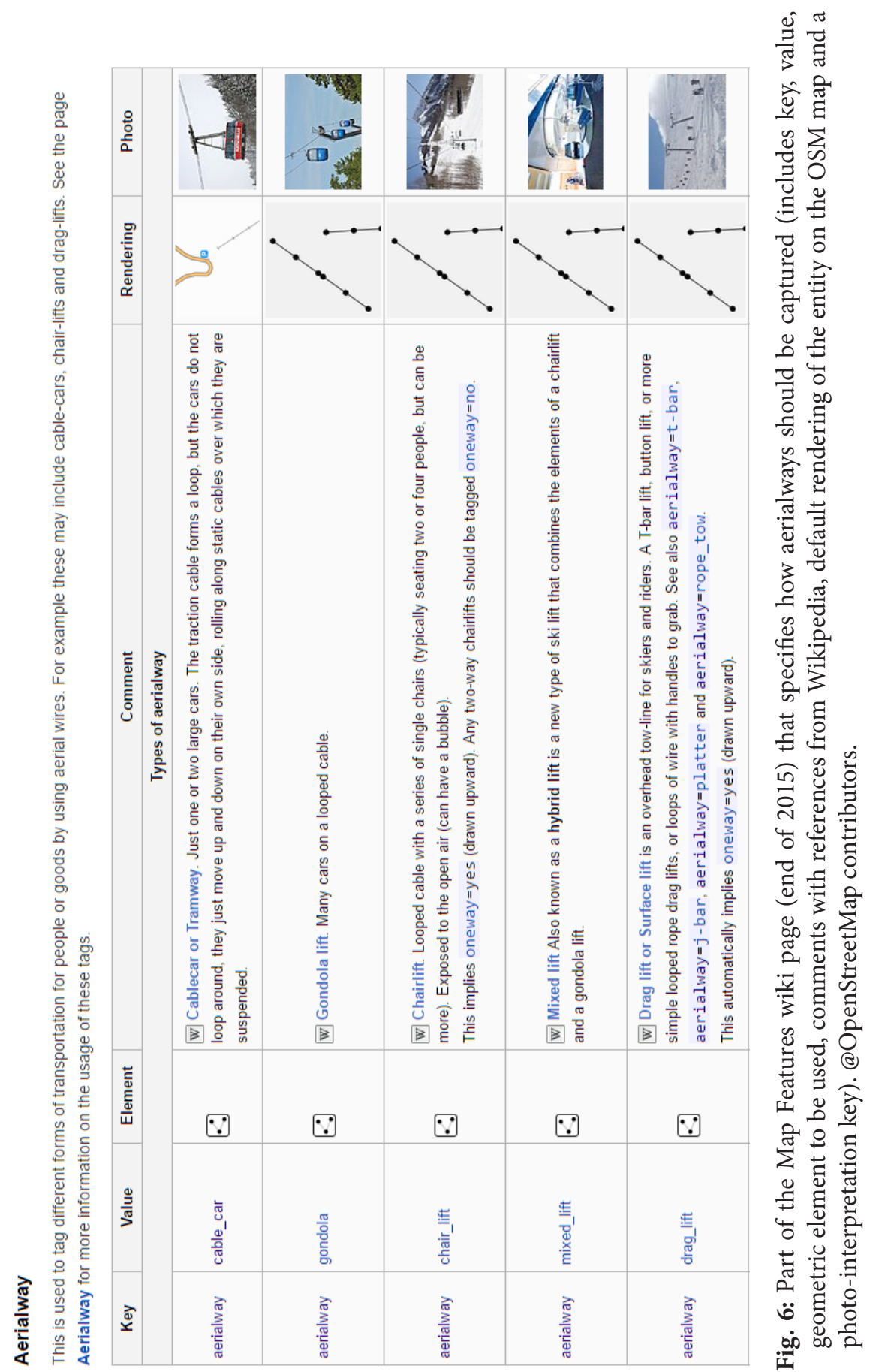


We have used these two examples to highlight the evolution of the OSM specification. From 2006 to 2015, each feature followed its own pace regarding the available information provided to the OSM community. Thus, the quality of the contributions for each feature could have varied accordingly. The mobilisation of thousands of enthusiastic, yet mostly inexperienced, contributors has inevitably led to 'learning-by-doing' in the face of incomplete and changing specifications.

\subsubsection{Changes in the In-depth Dimension}

The in-depth dimension of the 'Map Features' has been briefly discussed in the previous section. It refers to the available information for each key/value combination and the attribution process that contributors should follow. As explained, each physical entity has developed independently and the level of detail might vary considerably at different time periods. Here we provide one example to illustrate changes: unclassified roads. Figure 7 shows the unclassified roads wiki page at the end of 2008, which included the basic information regarding the mapping of the highway=unclassified combination.

In contrast, the same page at the end of 2015 (Figure 8) includes more detailed information about the preferable attributes that can be assigned to this entity as well as instructions about how to map the entity, when it is applicable, situations where other tags should be used, examples of determining applicability and even disambiguation instructions when the public/private status is unclear.

\subsubsection{Changes in Internationalisation}

Right from the beginning of the project, OSM aspired to create a global and free map. It is obvious that this could not be achieved without global participation. When examining the internationalisation of OSM, we can see that the 'Map Features' page is currently (i.e. in May 2016) available in 49 languages (Table 5). Although there has been no calculation regarding the percentage of the global population covered, it is clear that the basic rules of OSM can be understood by a broad audience. However, this was not always the case. Until the end of 2009, the 'Map Features' page was only available in English. From the end of 2010, however, until 2015, the number of available languages was 45 .

Apart from the 'Map Features' page, which is the starting point of the specification, there are documentation pages for each OSM key and value in order to better explain the use cases and the most appropriate combinations. These pages should also be available in as many languages as possible. However, their availability varies and, in general, there are considerably fewer available languages than for the 'Map Features' page. For example, the key aerialway is available in 10 languages (čeština, deutsch, english, italiano, magyar, polski, português do Brasil, русский, 한국어 and 日本語) while the combination amenity=cafe 


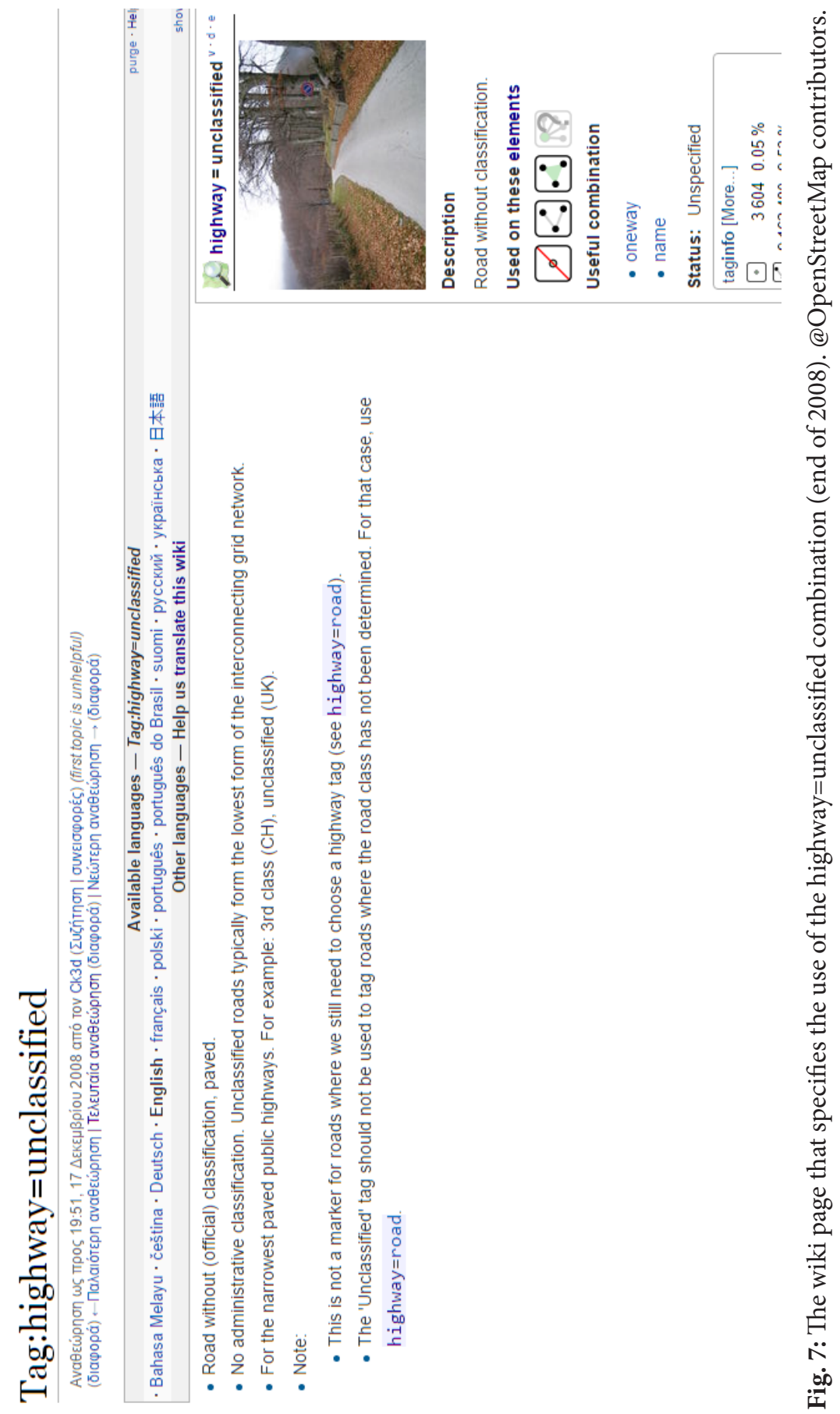




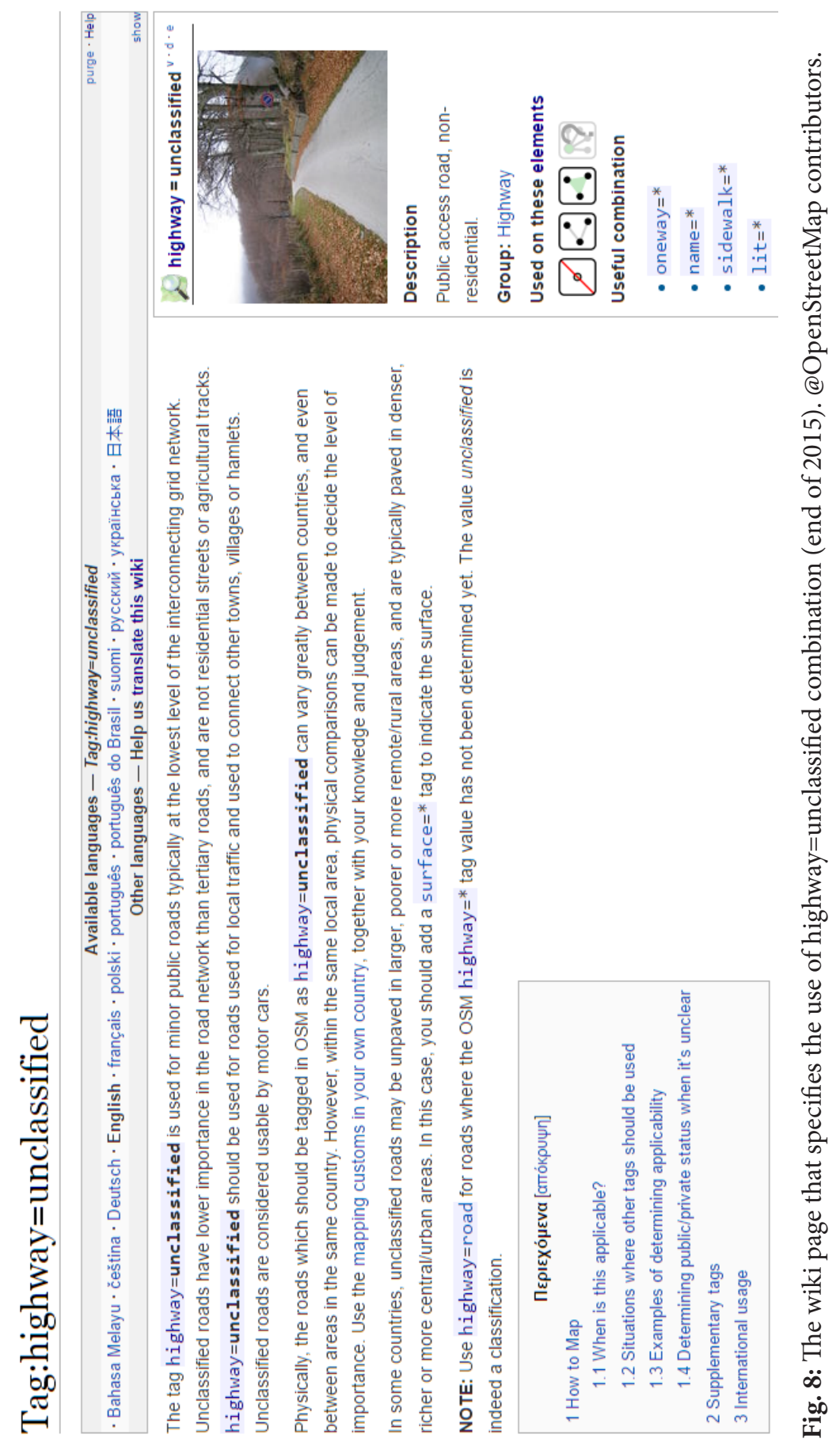


Table 5: Available languages for the Map Features wiki page (as of May 2016).

\begin{tabular}{|c|c|c|c|c|c|c|c|}
\hline$\#$ & Language & \# & Language & \# & Language & $\#$ & Language \\
\hline 1 & asturianu & 14 & Hrvatski & 27 & Română & 40 & $E \lambda \lambda \eta \nu \iota \kappa \alpha ́$ \\
\hline 2 & azərbaycanca & 15 & Íslenska & 28 & Shqip & 41 & jงங்о \\
\hline 3 & $\begin{array}{l}\text { Bahasa } \\
\text { indonesia }\end{array}$ & 16 & Italiano & 29 & Slovenčina & 42 & தமிழ் \\
\hline 4 & bosanski & 17 & kreyòl ayisyen & 30 & Slovenščina & 43 & 한국어 \\
\hline 5 & català & 18 & $\begin{array}{l}\text { kréyòl } \\
\text { gwadloupéyen }\end{array}$ & 31 & Suomi & 44 & 日本語 \\
\hline 6 & čeština & 19 & Latviešu & 32 & Svenska & 45 & 中文（简体） \\
\hline 7 & dansk & 20 & Lietuvių & 33 & Tiếng Việt & 46 & 中文（繁體） \\
\hline 8 & Deutsch & 21 & Magyar & 34 & Türkçe & 47 & עברית \\
\hline 9 & eesti & 22 & nederlands & 35 & српски/srpski & 48 & العربية \\
\hline 10 & english & 23 & norsk bokmål & 36 & Български & 49 & فارسى \\
\hline 11 & español & 24 & Polski & 37 & македонски & & \\
\hline 12 & esperanto & 25 & Português & 38 & Русский & & \\
\hline 13 & français & 26 & $\begin{array}{l}\text { português do } \\
\text { Brasil }\end{array}$ & 39 & Українська & & \\
\hline
\end{tabular}

is available in 12 languages (čeština, deutsch, eesti, english, français, italiano, nederlands, português do Brasil, русский, $\varepsilon \lambda \lambda \eta v \iota \kappa a ́$, 日本語, 中文（简体).

\section{Evolution of OSM Editors}

\subsection{The Usage of the OSM Editors}

An important component of the micro-environment of OSM is the editing tools. The OSM editors used by volunteers play an important role as they primarily dictate the type and quality of the data contributed. For example, an embedded functionality in an OSM editor can direct the volunteer to or avert them from specific choices that can improve or deteriorate the quality of the contribution. There are currently a large number of OSM editors available for various media, from online browser editors (e.g. iD and Potlatch 2), to desktop and offline editors such as JOSM and Merkaartor, to GIS software add-ons, e.g. for QGIS and ArcGIS, through to editors for mobile devices, like the Vespucci and OsmAndFrom. By reviewing the history of the OSM wiki pages dedicated to editors ${ }^{5}$, it becomes clear that the number of available editors has increased as the project has developed (Figure 9). 


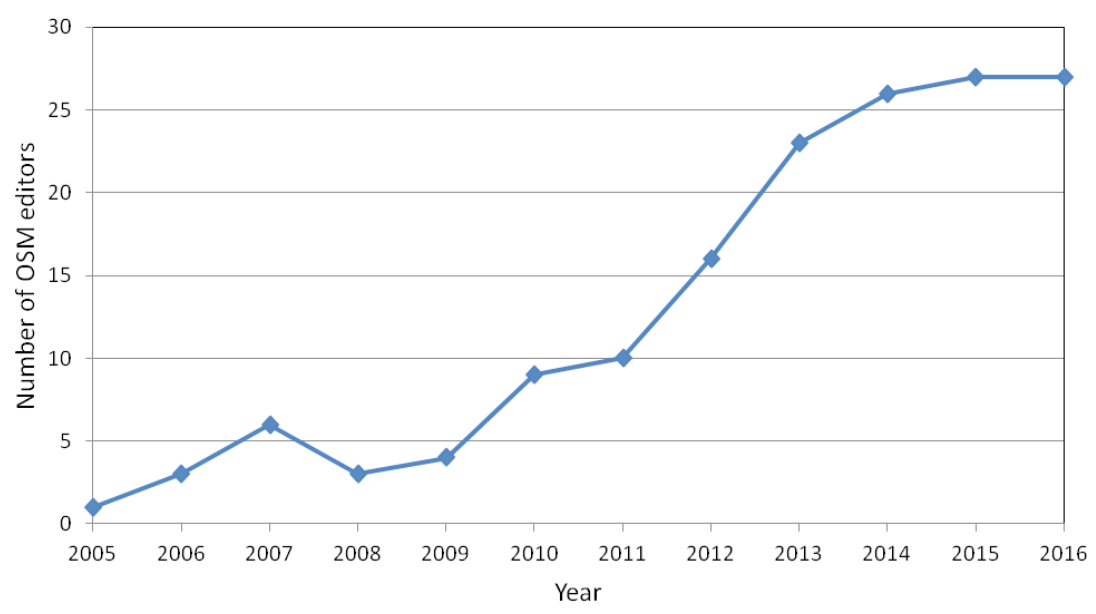

Fig. 9: Number of OSM editors.

The variety and the large number of OSM editors currently in use indicates the degree of interest in the OSM project. However, this wide range of OSM editors diversifies the data sources and can possibly affect the coherence and homogeneity of the contributions. Indeed, at the time of writing (i.e. May 2016), there were 27 editors available for the OSM community to choose from. This freedom, while in line with the ideology of a crowdsourced project, might undermine the overall effort for a usable dataset of high quality. However, the flip side of this observation might reside in the penetration that selected editors have in the OSM community. Indeed, by examining the statistics from the OSM wiki pages ${ }^{6}$ regarding the most popular editors, a more encouraging picture is painted. By using the number of changesets as a criterion for the years 2009 to 2015 (Figure 10), it can be seen that the most popular editors in 2015 are iD, JOSM and Potlatch 2. An OSM changeset is a group of changes made by a single user over a short period of time. One changeset might include a number of edits (see below) such as the addition of new elements and tags or a change in values.

While the OSM community seems to have settled on using primarily 3 out of the 27 editors available, the findings in Figure 10 raise concerns regarding the quality and homogeneity of the contributions submitted with other editors in the past. For example, Potlach 1, which used to be one of the most popular editors in 2009, is now abandoned, and Potlach 2 has been completely rewritten. Similarly, Merkaartor, which provided $4-5 \%$ of changesets each year from 2009 until 2011, has now almost entirely disappeared. Interestingly, purposebuilt editors for mobile devices have not managed to diffuse into the OSM community. For example, Vespucci has a small percentage, i.e. around 1\%. The most popular editor between 2009 and 2012 was JOSM, followed by the online 


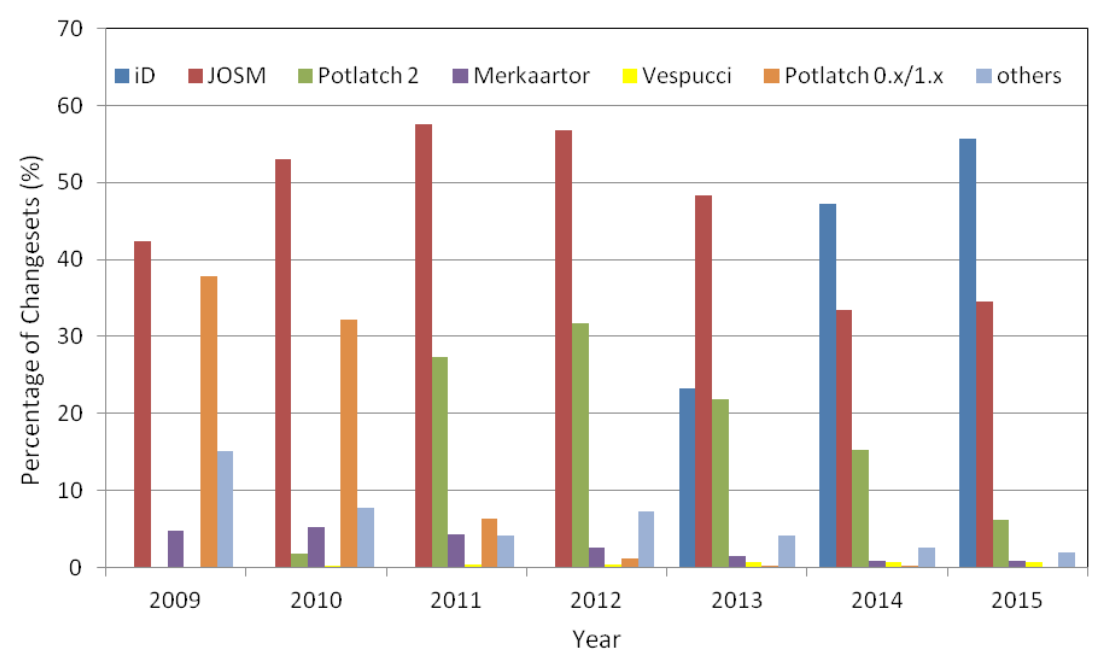

Fig. 10: Percentage of changesets per OSM editor.

editors on the OSM website: initially Potlatch 1, and then Potlatch 2 and iD. However, from 2014, iD has become the most frequently used editor when counting changesets. Yet when measuring the number of edits, JOSM has been the most popular editor since 2010 (Figure 11). Nevertheless, in 2015, JOSM use decreased by $5.6 \%$ while iD use has increased by $4.1 \%$.

From what has been presented so far, it is evident that there is a strong volatility in the choices of the OSM community. The majority of the changesets and edits take place through a small number of editors that succeed each other over time. While the aim of this chapter is not to compare and evaluate the functionality of each editor, it is to be noted that the potential differences in their functionality or abidance to the OSM specifications might cause inconsistencies and deteriorate the overall quality of the data submitted. However, on the positive side, the strength and devotion of the OSM community in creating new editors that adapt to new challenges and requirements can be seen.

\subsection{The Functionality of the Editors}

Apart from the number of OSM editors available, what has also changed is their functionality. The existence of a set of rules that function as a product specification also needs to be supported by the available tools for the task. Thus, the level and efficiency of the editors at any given point in time plays a crucial role in the quality of the contributions. Here we present the evolution of the functionality across the active editors from 2006 to the present: 


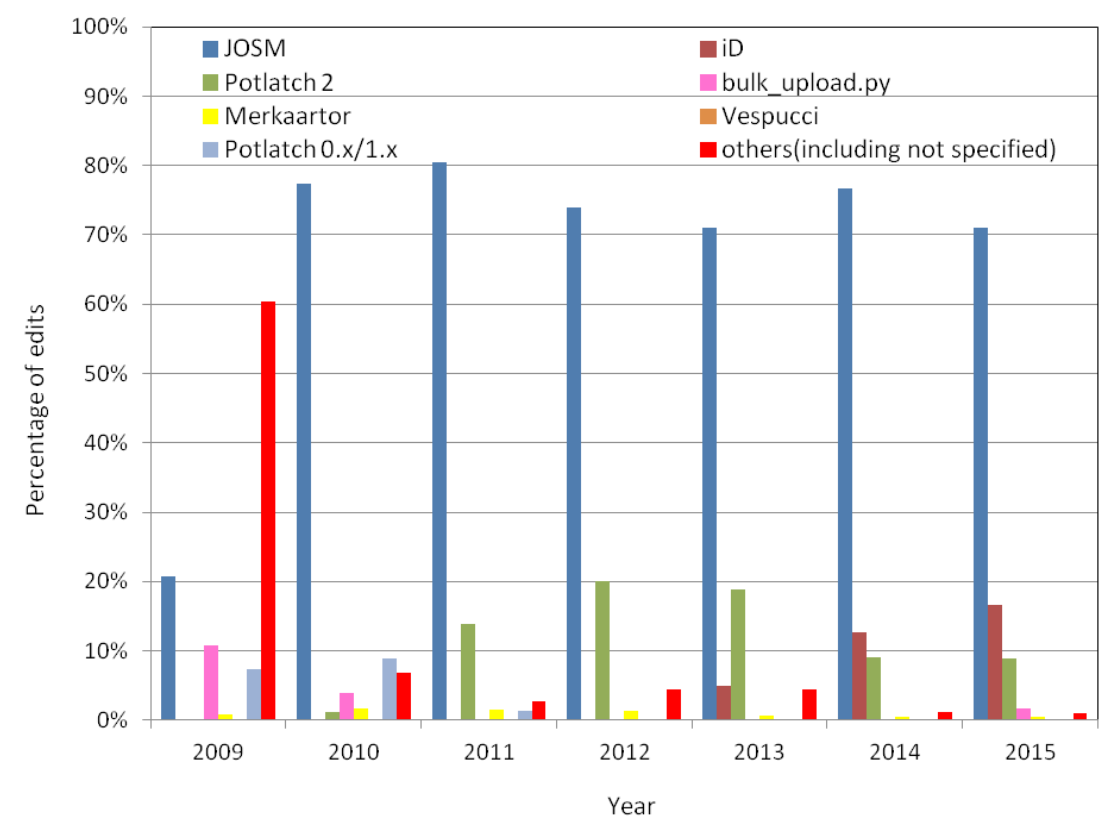

Fig. 11: Percentage of edits per OSM editor.

In 2006, the OSM editors serve only to upload GPS tracks. Only the online editing applet provides a Landsat photo, and thus GPS tracks cannot be verified in comparison with a satellite image.

- In 2007, Landsat overlay becomes available in JOSM 1.0 and some editing facilities are offered. Merkaartor, a small editor for OSM with some unique features like anti-aliased displaying and transparent display of map features, also appears.

- In 2007, the online editor applet displays Yahoo! Aerial Imagery under the GPS trackpoints while editing. This is very useful, and in fact more accurate than GPS data in the areas where coverage is most detailed (cities). In other areas it may sometimes assist in correcting GPS tracks.

- In 2008, photomapping is added in JOSM, which allows users to retrieve photographs and work with them on screen, positioned alongside the map data in the editor. In addition, if GPS location information is included in the photograph files or a GPS track is available, JOSM's photograph mapping features can be used to see them in context, and perhaps position new elements based on the recorded photograph positions.

- In 2008, Merkaartor can use satellite imagery from Yahoo! or any other Web Map Service (WMS). 
- In 2009, JOSM acquires fast fluid panning and zooming, which provides for precise mapping. It is now possible to work offline using downloaded data files, local photo and GPX files. Offline editing can help volunteers work more carefully in a less rushed manner, and thus could provide better contributions. In addition, advanced editing functionality, which improves positional accuracy, becomes available.

- In 2010, Yahoo! Aerial Imagery, Bing and other aerial imagery become available in JOSM as backgrounds for tracing. JOSM also supports audio mapping. Potlatch 2, a new version of the Potlatch editor, appears, offering quite a different editing experience. In addition to this, OSM cooperation with QGIS and Esri's ArcGIS leads to add-ons with very comprehensive GIS capabilities and advanced editing, further improving quality.

- In 2015, JOSM provides a large selection of aerial imagery and third-party GPS traces as backgrounds for tracing, as well as a built-in validator, which checks for common mapping errors before the data are uploaded. Tags are shown to users directly with links to the OSM wiki page, which returns information for a tag. In iD, custom aerial imagery can be used, photographs are directly available in the editor from Mapillary ${ }^{7}$, and OSM editors have access to billions of GPS tracks recorded by Strava ${ }^{8}$ users, which allows for very precise mapping of twisted roads and trails. Potlatch 2 develops advanced features, including vector backgrounds, a merging/conflation functionality for specialists and several aerial imagery backgrounds, which are preconfigured, as well as the introduction of an option for custom Tile Map Service (TMS) imagery.

- At the time of writing (May 2016), JOSM seems to be the most promising editor in terms of quality assurance based on the tools offered, such as advanced geometry and topology editing; the resolving of conflicts; the tagging of presets; a validator that checks for common mapping errors before data upload; selection of background images and custom TMS, WMS and Web Map Tile Service (WMTS); selection of third-party GPS traces immediately available as backgrounds for tracing; etc.

\section{Discussion and Conclusions}

It is not common for a discussion section to begin with what the study has not done. Yet, in this case, it is necessary. We only scratched the surface of what could be done. We sampled only a few of the 847 versions of just one wiki page, albeit an important one, and we used these to examine selected cases of the changes recorded. The entire OSM specification consists of hundreds more wiki pages with information about each feature and the possible key/ value combinations. Each of these extra pages have their history, which might, in turn, consist of hundreds of versions. The workload required to monitor 
each and every change would be immense. The other thing that we did not do is examine the OSM editor's evolution from a data quality viewpoint. This would require comparing the evolving functionality of all available editors against the active OSM specification at each point in time across a timeline; again, this is a task that would be next to impossible.

The value of this chapter is in its context and orientation. Regarding the former, the methodology chosen did not try to provide quantitative descriptions of different quality elements or indicators but rather to provide context and to expand the discussion on OSM quality by delving into the micro-environment of OSM. Indeed, we treated the 'Map Features' wiki page, the main OSM specification page and the OSM editors as living organisms and chose to examine how they have grown and evolved over time. By not studying and thus not fully understanding the environment within which OSM data are created, studies on the subject of data quality do not have a solid context, i.e. they deal with the symptoms and ignore the cause. This, in turn, leads us to orientation. VGI quality has become a popular subject of study among researchers. Much of the literature has focused on the nature of the phenomenon (Antoniou, 2011), on the contributors (Ciepłuch et al., 2011; Nedović-Budić and Budhathoki, 2010) and on the social engineering behind it (Haklay, 2010; Haklay et al., 2010; Zielstra and Zipf, 2010). Other, more technical papers have delved into statistics and measures of various quality elements and indicators (Barron et al., 2014; Keßler and de Groot, 2013), usually by comparing OSM data with authoritative products. In this chapter, the idea was to re-orient the discussion towards the fundamentals of spatial products. The specifications of a product and the tools available to produce it largely define the outcome, regardless of the effort, the workload or the enthusiasm put into producing it. OSM is clearly much more than a spatial product, and the value of VGI, in general, is orders of magnitude greater than the achieved quality (Antoniou, 2016). However, if the goal is to improve the quality of VGI, then we need to have a better understanding of the micro-environment within which each VGI project grows.

\section{Notes}

${ }^{1}$ https://www.mediawiki.org

${ }^{2}$ https://meta.wikimedia.org/wiki/Help:Minor_edit

${ }^{3}$ http://wiki.openstreetmap.org/wiki/Main_Page

${ }^{4}$ http://wiki.openstreetmap.org/wiki/Deprecated_features

${ }^{5} \mathrm{http}: / /$ wiki.openstreetmap.org/wiki/Editors

${ }^{6}$ http://wiki.openstreetmap.org/wiki/Editor_usage_stats

7 https://www.mapillary.com

${ }^{8}$ https://www.strava.com 


\section{Reference list}

Antoniou, V., 2016. Volunteered Geographic Information: Measuring Quality, Understanding the Value. Geomedia 20.

Antoniou, V., 2011. User Generated Spatial Content: An Analysis of the Phenomenon and its Challenges for Mapping Agencies. Unpublished $\mathrm{PhD}$ Thesis. University College London (UCL), London, UK.

Antoniou, V., Schlieder, C., 2014. Participation patterns, VGI and gamification, in: Proceedings of AGILE 2014. Presented at the AGILE 2014, Castellón, Spain, pp. 3-6.

Antoniou, V., Skopeliti, A., 2015. Measures and indicators of VGI quality: An overview, in: ISPRS Annals of the Photogrammetry, Remote Sensing and Spatial Information Sciences. Presented at the ISPRS Geospatial Week 2015, ISPRS Annals, La Grande Motte, France, pp. 345-351.

Barron, C., Neis, P., Zipf, A., 2014. A comprehensive framework for intrinsic OpenStreetMap quality analysis. Transactions in GIS 18, 877-895. DOI: https://doi.org/10.1111/tgis.12073

Brando, C., Bucher, B., 2010. Quality in user generated spatial content: A matter of specifications, in: Proceedings of the 13th AGILE International Conference on Geographic Information Science. Springer Verlag, Guimar aes, Portugal, pp. 11-14.

Brando, C., Bucher, B., Abadie, N., 2011. Specifications for user generated spatial content, in: Geertman, S., Reinhardt, W., Toppen, F. (Eds.), Advancing Geoinformation Science for a Changing World, Lecture Notes in Geoinformation and Cartography. Springer Berlin Heidelberg, pp. 479-495.

Ciepłuch, B., Mooney, P., Winstanley, A., 2011. Building generic quality indicators for OpenStreetMap, in: Proceedings of the 19th Annual GIS Research UK (GISRUK) Conference. Portsmouth, England, 27-29 April 2011. Available at: http://eprintsprod.nuim.ie/2483/1/Gisruk2011-edit2-Blazej.pdf [Last accessed 16 May 2017].

Clinton, W., 2000. Improving the civilian global positioning system (GPS). The White House, Office of Science \& Technology Policy: Washington, D.C., USA. Available at: https://clinton4.nara.gov/WH/EOP/OSTP/html/0053_4. html [Last accessed 16 May 2017].

D’Antonio, F., Fogliaroni, P., Kauppinen, T., 2014. VGI edit history reveals data trustworthiness and user reputation, in: Huerta, J., Schade, S., Granell, G. (eds.), Proceedings of the 17th AGILE International Conference on Geographic Information Science: Connecting a Digital Europe through Location and Place, Castellón, Spain, 3-6 June 2014, Available at: https://agile-online. org/conference_paper/cds/agile_2014/agile2014_140.pdf Last accessed 16 May 2017].

Fonte, C C, Antoniou, V, Bastin, L, Estima, J, Arsanjani, J J, Bayas, J-C L, See, L and Vatseva, R. 2017. Assessing VGI Data Quality. In: Foody, G, See, L, Fritz, S, Mooney, P, Olteanu-Raimond, A-M, Fonte, C C and Antoniou, V. (eds.) 
Mapping and the Citizen Sensor. Pp. 137-163. London: Ubiquity Press. DOI: https://doi.org/10.5334/bbf.g.

Girres, J.-F., Touya, G., 2010. Quality assessment of the French OpenStreetMap dataset. Transactions in GIS 14, 435-459.

Goodchild, M.F., 2007. Citizens as sensors: the world of volunteered geography. GeoJournal 69, 211-221. DOI: https://doi.org/10.1007/s10708-007-9111-y

Haklay, M., 2013. Citizen science and volunteered geographic information: Overview and typology of participation, in: Sui, D., Elwood, S., Goodchild, M. (Eds.), Crowdsourcing Geographic Knowledge. Springer Netherlands, Dordrecht, Netherlands, pp. 105-122.

Haklay, M., 2010. How good is volunteered geographical information? A comparative study of OpenStreetMap and Ordnance Survey datasets. Environment and Planning B: Planning and Design 37, 682-703. DOI: https://doi. org/10.1068/b35097

Haklay, M., Basiouka, S., Antoniou, V., Ather, A., 2010. How many volunteers does it take to map an area well? The validity of Linus' Law to volunteered geographic information. The Cartographic Journal 47, 315-322.

ISO, 2005. ISO 9000: Quality Management Systems - Fundamentals and Vocabulary. International Organisation for Standardisation (ISO), Geneva, Switzerland.

Jokar Arsanjani, J., Mooney, P., Zipf, A., Schauss, A., 2015. Quality assessment of the contributed land use information from OpenStreetMap versus authoritative datasets, in: Jokar Arsanjani, J., Zipf, A., Mooney, P., Helbich, M. (Eds.), OpenStreetMap in GIScience, Lecture Notes in Geoinformation and Cartography. Springer International Publishing, Cham, pp. 37-58.

Keßler, C., de Groot, R.T.A., 2013. Trust as a proxy measure for the quality of Volunteered Geographic Information in the case of OpenStreetMap, in: Vandenbroucke, D., Bucher, B., Crompvoets, J. (Eds.), Geographic Information Science at the Heart of Europe. Springer International Publishing, Cham, pp. 21-37.

Minghini, M, Antoniou, V, Fonte, C C, Estima, J, Olteanu-Raimond, A-M, See, L, Laakso, M, Skopeliti, A, Mooney, P, Arsanjani, J J, Lupia, F. 2017. The Relevance of Protocols for VGI Collection. In: Foody, G, See, L, Fritz, S, Mooney, P, Olteanu-Raimond, A-M, Fonte, C C and Antoniou, V. (eds.) Mapping and the Citizen Sensor. Pp. 223-247. London: Ubiquity Press. DOI: https://doi.org/10.5334/bbf.j.

Nedović-Budić, Z., \& Budhathoki, U. N. R., 2010. Motives for VGI Participants, in: 'VGI for SDI' Workshop, Wageningen University, Netherlands, 16 April 2010. Available at: https://www.wur.nl/upload_mm/9/b/1/4deca512-70054974-8974-2d9b234c6eb0_Zorica_Nama_VGI_for_SDI.pdf [Last accessed 16 May 2017].

Olteanu-Raimond, A-M, Laakso, M, Antoniou, V, Fonte, C C, Fonseca, A, Grus, M, Harding, J, Kellenberger, T, Minghini, M, Skopeliti, A. 2017. VGI in National Mapping Agencies: Experiences and Recommendations. 
In: Foody, G, See, L, Fritz, S, Mooney, P, Olteanu-Raimond, A-M, Fonte, C C and Antoniou, V. (eds.) Mapping and the Citizen Sensor. Pp. 299-326. London: Ubiquity Press. DOI: https://doi.org/10.5334/bbf.m.

OpenStreetMap, 2016. Map Features, 18 November 2016. Available at http:// wiki.openstreetmap.org/wiki/Map_Features [Last accessed 4 April 2017]

Ordnance Survey (OS), 2001. OS MasterMap ${ }^{\text {TM }}$ real-world object catalogue, 2001. Available at https://www.ordnancesurvey.co.uk/docs/legends/osmastermap-real-world-object-catalogue.pdf [Last accessed 4 April 2017]

O'Reilly, T., 2007. What is Web 2.0: Design patterns and business models for the next generation of software. Communications \& Strategies 65, 17-37.

See, L, Estima, J, Pőd.r, A, Arsanjani, J J, Bayas, J-C L and Vatseva, R. 2017. Sources of VGI for Mapping. In: Foody, G, See, L, Fritz, S, Mooney, P, Olteanu-Raimond, A-M, Fonte, C C and Antoniou, V. (eds.) Mapping and the Citizen Sensor. Pp. 13-35. London: Ubiquity Press. DOI: https://doi. org/10.5334/bbf.b.

Skopeliti, A, Antoniou, V and Bandrova, T. 2017. Visualisation and Communication of VGI Quality. In: Foody, G, See, L, Fritz, S, Mooney, P, Olteanu-Raimond, A-M, Fonte, C C and Antoniou, V. (eds.) Mapping and the Citizen Sensor. Pp. 197-222. London: Ubiquity Press. DOI: https://doi. org/10.5334/bbf.i.

van Exel, M., Dias, E., Fruijtier, S., 2010. The impact of crowdsourcing on spatial data quality indicators, in: Wallgrün, J.O., Lautenschütz, A.K. (eds.), Proceedings of the GIScience 2010 Doctoral Colloquium, Zurich, Switzerland, 14-17 September 2010, Akademische Verlagsgesellschaft Aka GmbH (IOS Press), Heidelberg, Germany. Available at: http://www.giscience2010. org/pdfs/paper_213.pdf [Last accessed 16 May 2017].

Vandecasteele, A., Devillers, R., 2015. Improving volunteered geographic information quality using a tag recommender system: The case of OpenStreetMap, in: Jokar Arsanjani, J., Zipf, A., Mooney, P., Helbich, M. (Eds.), OpenStreetMap in GIScience, Lecture Notes in Geoinformation and Cartography. Springer International Publishing, Cham, Switzerland, pp. 59-80.

Zielstra, D., Zipf, A., 2010. A comparative study of proprietary geodata and volunteered geographic information for Germany, in: Painho, M., Santos, M., Y., Pundt, H. (eds.), Proceedings of the 13th AGILE International Conference on Geographic Information Science: Geospatial Thinking, Guimarães, Portugal, 11-14 May 2010, pp. 1-15. Available at: https://agile-online. org/Conference_Paper/CDs/agile_2010/ShortPapers_PDF/142_DOC.pdf [Last accessed 16 May 2017]. 